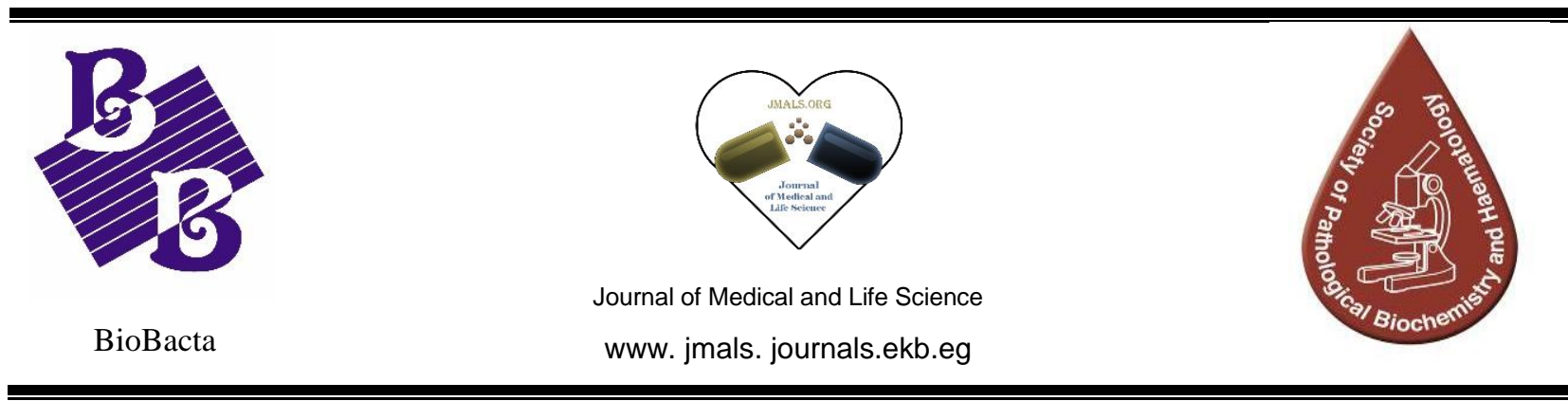

\title{
Arabic gum ameliorates histological and histochemical changes in the renal cortex of rats induced by alloxan injection
}

\section{Rasha Mohammed Ibrahim ${ }^{1}$, Hemmat Mansour Abdelhafez ${ }^{1}$, Fatma Ahmed Eid ${ }^{1}$, and Sawsan Abd EL-Maksoud ELShamy ${ }^{2}$}

\author{
${ }^{1}$ Zoology Department, Faculty of Science, AL-Azhar University, Egypt \\ ${ }^{2}$ Misr University for Science and Technology, Egypt
}

Corresponding author: Rasha Mohammed Ibrahim: rashamohammed186@gmail.com, Telephone: 01151379007

DOI: $10.21608 /$ jmals.2020.133543

\begin{abstract}
$\underline{\text { Abstract }}$
Arabic gum (AG) is a natural branched-chain multifunctional hydrocolloid with a highly neutral or slightly acidic, arabinogalactan protein complex containing calcium, magnesium, and potassium. Arabic gum is a dried exudate obtained from the stem and branches of Acacia trees. AG has an anti-inflammatory and antioxidant effect. This study aimed to examine the possible anti-inflammatory and antioxidant effect of AG against the damage induced by alloxan injection on renal tissue of adult male rats using histological and histochemical studies. The current experiment was carried out on 48 adult male Albino rats. Rats were randomly and equally categorized into four groups 12 rats in each group as follows: 1) Control group (C): rats have left without treatment; 2) Diabetic groups (D): rats were injected with $150 \mathrm{mg} / \mathrm{kg}$ body weight of alloxan and left for 21 days ; 3) Arabic gum groups (G): rats were orally administrated AG (25 mg/kg body weight/day) for 21 days and 4) D+G groups: rats were injected with alloxan and treated with $25 \mathrm{mg} / \mathrm{kg}$ body weight/day for 21 days. The experimental rats were sacrificed after 7 and 21 days post-treatment. Examination of renal tissue of rats seven and twenty-one days post-alloxan injection revealed many histological and histochemical changes. Highly increased collagen fibres were demonstrated after seven and twenty-one days post alloxan injection. Also, alloxan injection significantly decreased PAS-positive materials, total protein content, and total DNA content, but it significantly increased amyloid $\beta$-protein content relative to the control group. While treatment with AG post-alloxan injection showed a trend toward lowering the incidence of renal tissue histological and histochemical changes induced by alloxan injection. According to the results obtained in the current study using AG as a natural agent showed a strong cytoprotective effect against the histological and histochemical changes due to its antioxidant effect.
\end{abstract}

Keywords: Alloxan, Arabic gum, histology, histochemistry, rats. 


\section{1-Introduction}

Diabetes mellitus (DM) includes a group of chronic metabolic diseases involving hyperglycemia which, over prolonged periods, leads to injury in various tissues of the body (Atar and Hanssen, 2017; Gentile et al., 2017). Over $90 \%$ of diabetes mellitus patients are type $2 \mathrm{DM}$ (T2DM) patients. Thus, we must explore a way to reduce the number of individuals with T2DM (Zou et al., 2018). Accumulated evidence shows that intermediate phenotypes, such as body mass index (Zhang et al., 2017; Cheng et al., 2018a), systolic blood pressure (Svensson et al., 2017), and circulating uric acid (Xu et al., 2016) are responsible for the onset of this type of DM (Cheng et al., 2018b). In both type 1 and type 2 diabetes, various genetic and environmental factors can result in the progressive loss of $\beta$-cell mass and/or function that manifests clinically as hyperglycemia. Once hyperglycemia occurs, patients with all forms of diabetes are at risk for developing the same chronic complications, although rates of progression may differ. The identification of individualized therapies for diabetes in the future will require a better characterization of the many paths to $\beta$-cell demise or dysfunction (Skyler et al., 2017).

Konstantinos (2006) reported that $\mathrm{T} 2 \mathrm{DM}$ is a heterogeneous syndrome with a complex interaction of genetic and environmental factors that affect multiple phenotypic manifestations in the body such as insulin secretion and action, pancreatic $\beta$ cell mass, distribution of body fat, and development of obesity. The author added that T2 DM is generally characterized by two main pathophysiologic entities: i) resistance to the action of insulin and ii) insufficient secretion of insulin from the $\beta$ cells of the pancreas. Both of these pathophysiologic disturbances (insufficient secretion and peripheral insulin resistance) are thought to be necessary for the development of the disease. Bastos et al. (2012) suggested that sedentary lifestyles as well as high caloric diets are key factors in developing obesity and type 2 diabetes and that oxidative and nitrosative stress are common factors in the physiopathology of both of these metabolic diseases. They added that oxidative and nitrosative stress is thought to play a key role in the pathogenesis of these metabolic diseases and their complications; importantly, oxidative and nitrosative stress has been associated with increased insulin resistance in animal models as well as in type 2 diabetes in obese human patients.

Type 2 diabetes mellitus is a progressive and complex metabolic disorder that is associated with a risk of developing microvascular and macrovascular complications when blood glucose is not adequately controlled (Yokoyama et al., 2016). Chronic hyperglycemia leads to microvascular complications in patients with T2DM including kidney disease, retinopathy, and neuropathy (Wanner, 2017). It is estimated that more than 20 and up to $40 \%$ of diabetic patients can develop chronic kidney disease (Papadopoulou-Marketou et al., 2018). Hyperglycemia facilitated the generation of ROS in different renal cells, such as tubular cells, and high glucose-induced proliferation and activation of renal fibroblasts were mediated by ROS signaling (He et al., 2016).

Despite the presence of known antidiabetic medicine in the pharmaceutical market, diabetes and the related complications continued to be a major medical problem. Some medicinal plants have been reported to be useful in diabetes worldwide and have been used empirically as antidiabetic and antihyperlipidemic remedies (Salgueiro et al., 2018; Morad and Mohamed, 2020). Moreover, traditional or alternative medicine is considered an important source of future therapeutic agents to treat many diseases including DM (Kumar et al., 2011). The extracts of several medicinal plants revealed potent antidiabetic activity using animal models and can minimize complications of diabetes (Ayeleso et al., 2018; Jiang et al., 2020). Arabic Gum is a natural branched-chain multifunctional hydrocolloid with a highly neutral or slightly acidic, arabinogalactan protein complex containing calcium, magnesium, and 
potassium (Renard et al., 2006). Arabic gum which is defined as A. seyal and A. senegal enters many areas in medicine to treat many diseases and is used in many industries such as yogurt, soda, water, and cosmetics (Mohamed, 2010). Dietary fibers have no clear nutritional role, but they play an important role in preventing many common diseases such as colon cancer, DM, coronary thrombosis, obesity, and chronic kidney failure (Nishi and Jayakrishnan, 2004).

\section{2-Materials and Methods}

\section{1-Experimental animals}

A total of 48 adult male Sprague-Dawley rats weighing approximately 120-160 grams each were used for the present study. The animals were obtained from the animal house of the Egyptian Holding Company for Biological Products and Vaccines (Cairo-Helwan, Egypt). Two weeks before the experimental work, the rats were maintained in the laboratory and housed in specially constructed and cleaned cages (six rats per cage) and kept under regulated temperature and light conditions (12 hours of light:12 hours of darkness) and adequate ventilation. Moreover, they were fed a normal diet and water ad libitum.

\section{2-Experimental design}

The rats were equally categorized into four groups (12 rats in each group) as follows: group 1-Healthy untreated control rats. (C), group 2rats injected with alloxan and left for 21 days (D), group 3 - rats orally administered AG (G) (25 $\mathrm{mg} / \mathrm{kg}$ body weight/day) for 21 days, and group 4 rats injected with alloxan and treated for 21 days with $25 \mathrm{mg} / \mathrm{kg}$ body weight AG per day (D + G). After 7 and 21 days of treatment, the experimental rats were sacrificed.

\section{3-Diabetic model (induction of diabetes)}

Alloxan was obtained from Al-Gomhouria Company. Male rats were fasted overnight for at least 8 hours. DM was induced by the intraperitoneal injection of a single dose of alloxan monohydrate (150 mg/kg body weight), which was dissolved in normal saline (Misra and Aiman, 2012). The blood glucose levels were measured by a glucometer after 48-hour post-alloxan injection, and rats with fasting blood glucose levels above $250 \mathrm{mg} / \mathrm{dl}$ were classified as diabetic (Waer and Helmy, 2012).

\section{4-Preparation of Arabic gum solution}

AG is a soluble dietary fibre derived from the stems and branches of Acacia arabica trees, naturally. It was obtained from Al-Gomhouria Company as a fine powder for this study. According to Gamal El-din et al. (2003) AG's aqueous solution was prepared freshly each day and given orally through a gastric tube at a dosage of 25 $\mathrm{gm} / \mathrm{kg} / \mathrm{day}$. The dose for rats was estimated based on a human dose using Paget's formula (Paget and Barnes, 1964).

\section{5-Histological and histochemical techniques}

After 7 and 21 days, the control and all treated groups were sacrificed, and then the kidneys were quickly removed and fixed for 24 hours in 10 percent neutral formalin followed by dehydration in ascending grades of alcohol, clearing in xylene, and embedding in paraffin wax. The sections were then cut at a thickness of $5 \mu$ using a microtome (SLEE MAINZ-Cut 4050Microtome- Lise-Meitner-Str-155129-Germany) and stained with Mallory's trichrome stain for detection of collagen fibres (Pears, 1977), Periodic acid Schiff's technique for detection of PAS-positive materials (Drury and Wallington, 1980), mercuric bromophenol blue method for detection of total protein (Mazia et al., 1953), Feulgen reaction for detection of DNA (Drury and Wallington, 1980) and Congo red technique for detection of amyloid protein (Valle, 1986).

\section{6-Quantitative histochemical analysis}

The optical density of histochemically PAS, mercuric bromophenol blue, Feulgen, and Congo red-stained sections of kidney and pancreas of the 
control and treated groups was recorded using IPWIN 32 image analysis software. The mean optical density was used to compare the PAS-positive content, total protein content, total DNA content, and amyloid- $\beta$ protein content of the different groups. The comparison was established as the mean of the treated group value with the control group.

\section{7- Laboratory facilities}

Facilities including animal housing had been made available by the Center for Genetic Engineering, Faculty of Science, Al-Azhar University (Boys). Histological, histochemical, and quantitative image analyses were performed in the Department of Zoology, Faculty of Science, AlAzhar University (Girls).

\section{$\underline{\text { 3-Results }}$}

\section{$\underline{\text { 3.1- Histological results }}$}

Sections of kidney cortex tissue were stained with Mallory's trichrome stain for detection of collagen fibres. Normal distribution of collagen fibres in sections of the kidney cortex of the control male Albino rats was shown in fig.1 A. Collagen fibres are realized in Bowman's capsules, brush borders of the proximal convoluted tubules, glomeruli, and the basement membranes of the convoluted tubules. While, highly increased collagen fibres were demonstrated after seven days post alloxan injection in Bowman's capsules, glomeruli, in between the convoluted tubules and in their basement membranes, in and around the highly dilated and congested renal arteries and in the degenerated area between the convoluted tubules (Fig. 1B). By the end of twenty-one days following alloxan injection, highly increased collagen fibres were also detected in and around the highly dilated and congested renal artery, around the highly distorted glomerulus, around the hemorrhagic area, in the basement membranes of convoluted tubules, and between them (Fig. 1C).

Normal distribution of collagen fibres which support the glomeruli, Bowman's capsules, basement membranes of the proximal and distal convoluted tubules of the kidney cortex of the Arabic gum groups were detected after seven (Fig.1D) and twenty-one days post-treatment with Arabic gum (Fig. 1E). Also, an examination of kidney cortex tissue of rats administrated Arabic gum post-alloxan injection showed slightly increased collagen fibres deposition in between the convoluted tubules and in their basement membrane after seven days as compared to the control group (Fig.1F). While thin scattered collagen fibres that supported the glomeruli and convoluted tubules were observed after twenty-oneday (Fig. 1G). 

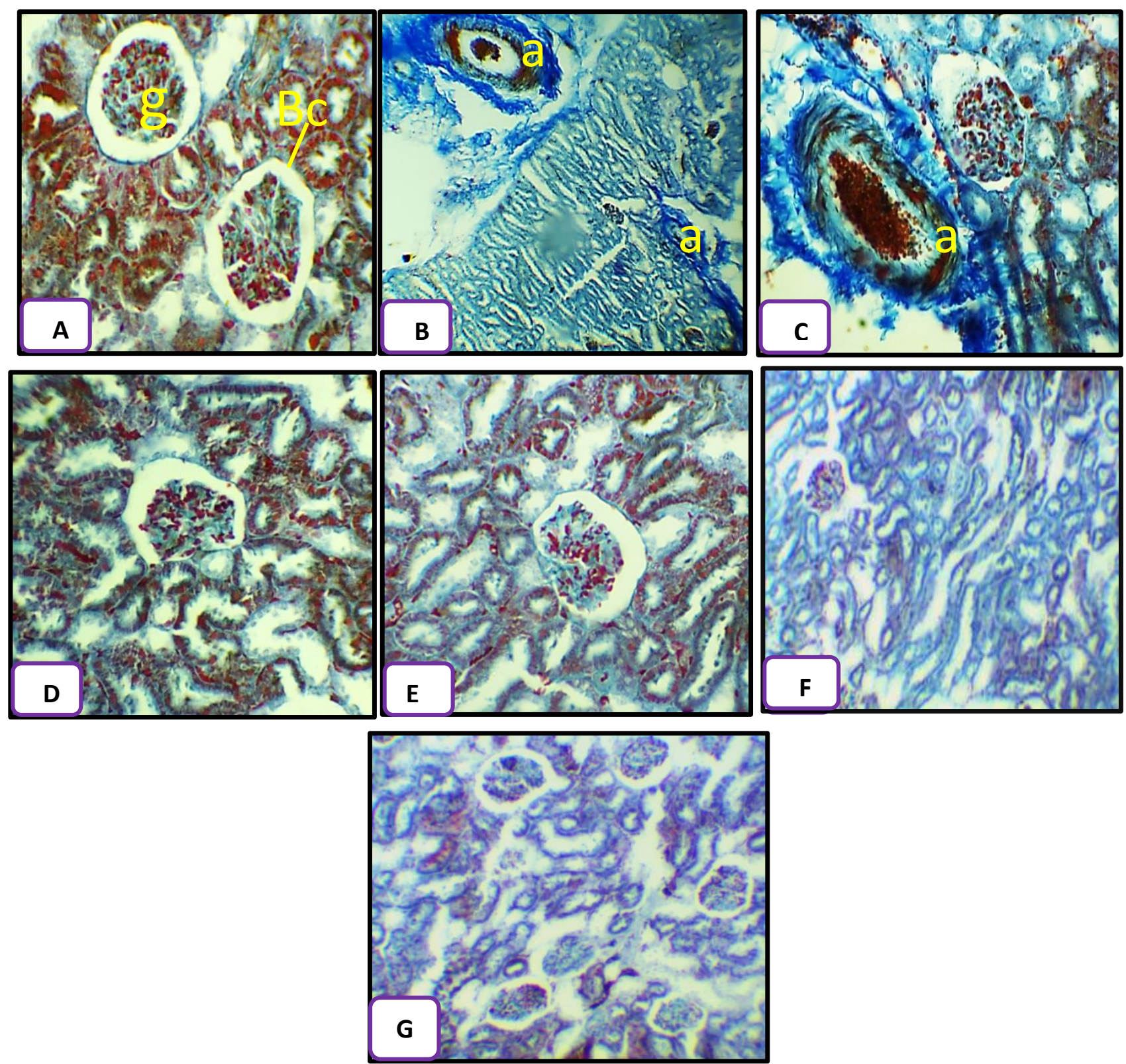

Figs. 1A-G- Photomicrographs of sections in kidney cortex tissue of the control and all the treated groups stained with Mallory's trichrome stain. A- Showing thin collagen fibres support Bowman's capsules (Bc), glomeruli (g), and the basement membranes of the convoluted tubules of the control group. B, C- Showing highly increased collagen fibres in Bowman's capsules, glomeruli, in between the convoluted tubules and in their basement membranes, in and around the highly dilated and congested renal arteries (a) and in the degenerated area between the convoluted tubules of the diabetic groups after seven (Fig. 1B) and twenty-one days (Fig. 1C). D, E- Showing nearly normal distribution of collagen fibres of Arabic gum groups after seven (Fig. 1D) and twenty on days (Fig. 1E). F, G- Showing slightly increased collagen deposition in between the convoluted tubules and in their basement membranes of groups administrated Arabic gum post alloxan injection for seven days (Fig. 1F), while thin scattered collagen fibres are observed after twenty-one days (Fig. 1G) as compared to the control group. (A, C, D, E X 400 ; B, F, G X 250). 


\section{2-Histochemical results}

\subsection{1- PAS-positive materials}

Table 1 and figures 2- 3 illustrated the changes in PAS-positive materials in sections of kidney cortex tissue of the control and the different experimental groups after seven and twenty-one days posttreatment. The diabetic groups exhibited a significant decrease in PAS-positive materials (0.091\&0.093 after seven and twenty-one days respectively) in the cuboidal cells of the proximal and distal convoluted tubules, but lobulated glomeruli were deeply stained after seven (Fig. 3B) and twenty-one days (Fig. 3C).
While Arabic gum treated groups exhibited nonsignificant changes in PAS-positive materials which reached $0.441 \& 0.425$ after seven (Fig. 3D) and twenty-one days (Fig. 3E) respectively as compared to the control group. $\mathbf{D + G}$ group after seven days underwent a significant decrease in PAS +ve materials which reached 0.349 (Fig. 3F), on the other hand, D+G after twenty-one-day exhibited a nonsignificant decrease in PAS-positive materials which amounted to 0.424 (Fig. 3G) as compared to the control value.

\begin{tabular}{||l||c|c|c|c||}
\hline \multicolumn{1}{||c|}{ Parameters } & \multicolumn{4}{c|}{ PAS-positive materials } \\
\hline \multirow{2}{*}{ Time } & \multicolumn{3}{c|}{ Seven days } & \multicolumn{2}{c|}{ Twenty-one days } \\
\cline { 2 - 5 } Groups & Mean \pm S.D & $\begin{array}{l}\% \text { Change } \\
\text { vs control }\end{array}$ & Mean \pm S.D & $\begin{array}{c}\% \text { Change } \\
\text { vs control }\end{array}$ \\
\hline \hline Control (C) & $0.431 \pm 0.021$ & $0.0 \%$ & $0.431 \pm 0.021$ & $0.0 \%$ \\
\hline Diabetic group (D) & $0.091 * \pm 0.013$ & $-78.89 \%$ & $0.093 * \pm 0.012$ & $-78.42 \%$ \\
\hline Arabic gum(G) & $0.441 \pm 0.074$ & $2.32 \%$ & $0.425 \pm 0.050$ & $-1.39 \%$ \\
\hline D+G & $0.349 * \pm 0.028$ & $-19.03 \%$ & $0.424 \pm 0.063$ & $-1.62 \%$ \\
\hline
\end{tabular}

Table 1- Showing PAS-positive materials in kidney cortex tissue of the control and all the treated groups of adult male Albino rats -Each value represents the mean \pm standard deviation (SD)

-* Significant difference from the control at $\mathrm{P} \leq 0.05$

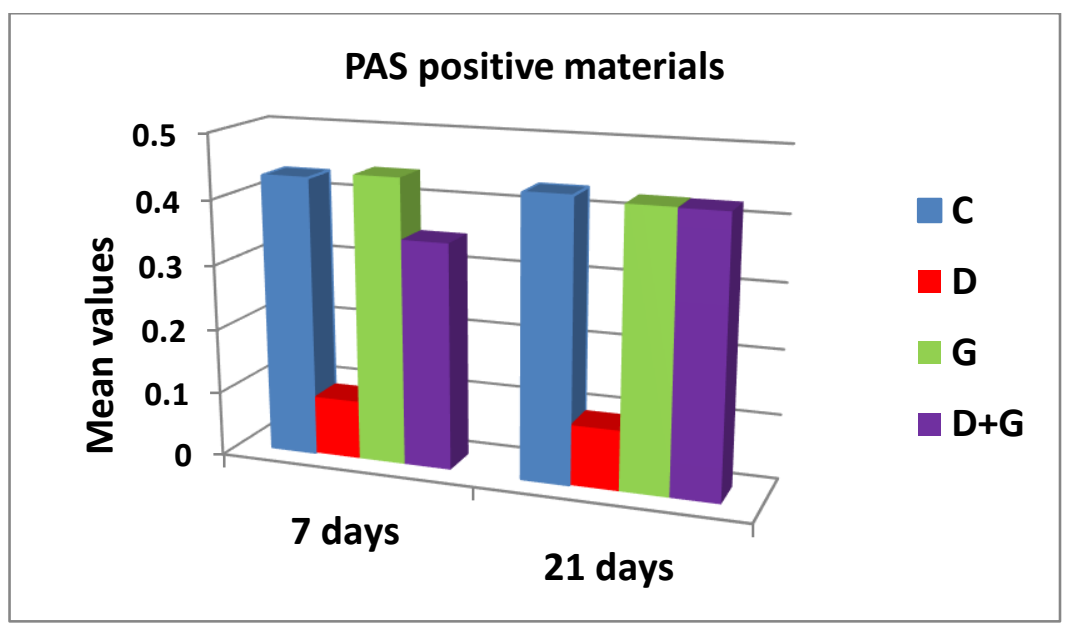

Fig. 2- Showing the mean values of PAS-positive materials relative to the control value 

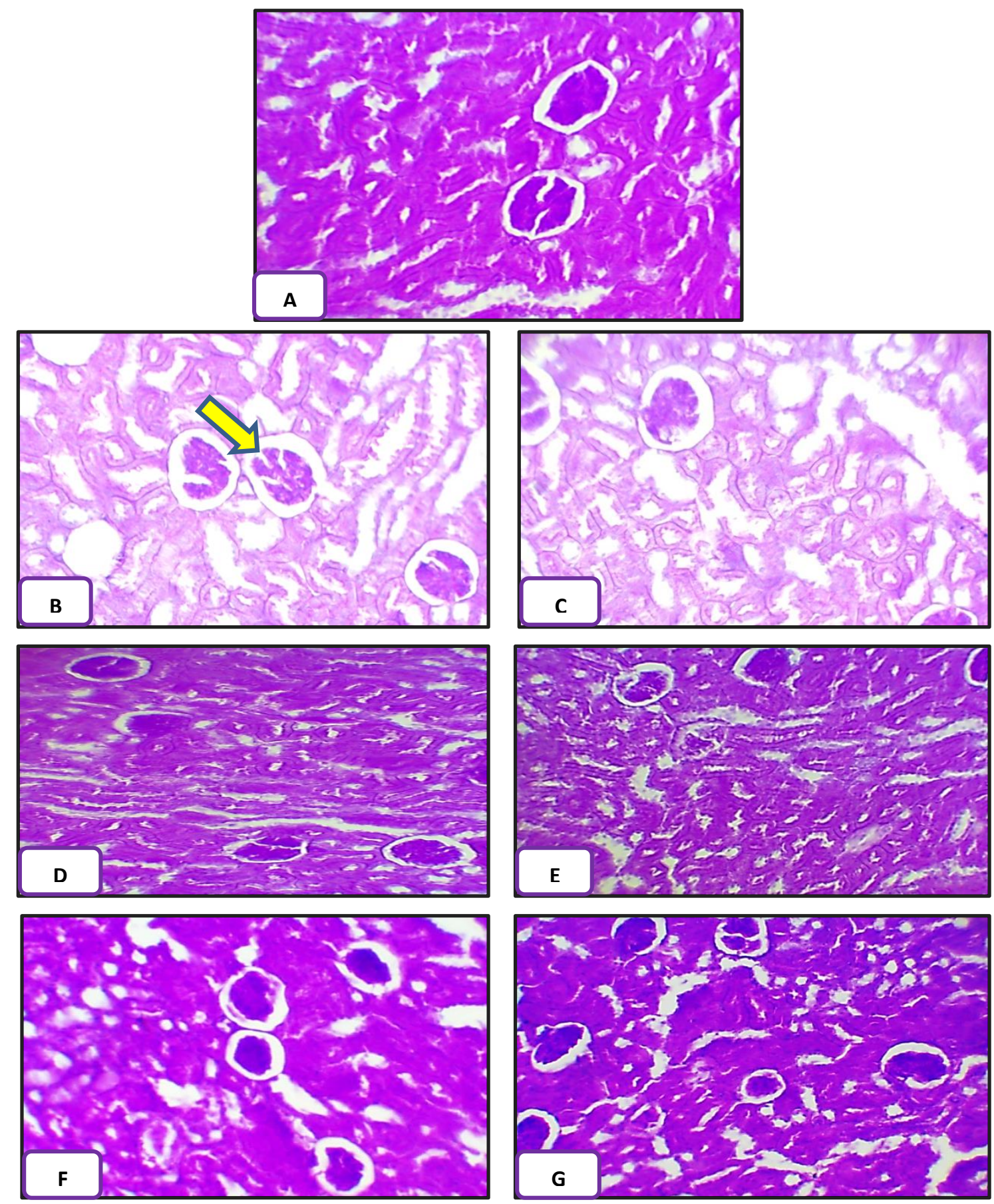

Figs. 3A-G- Photomicrographs showing the distribution of PAS + materials in sections of the kidney cortex tissue of the control and all the treated groups (PAS stain X 250)

A- Showing densely stained PAS + materials in the glomerulus, basement membranes, convoluted tubules, and brush borders of the proximal tubule of the control group. B, C-Showing faintly stained polysaccharides in the cuboidal cells of the proximal and distal convoluted tubules in the kidney cortex of the diabetic groups, but lobulated $(\rightarrow)$ glomeruli are deeply stained after seven (Fig. 3B) and twenty-one day (Fig. 3C). D, E- Showing normal distribution of polysaccharides in the glomeruli and convoluted tubules of Arabic gum groups after seven (Fig. 3D) and twenty-one days (Fig. 3E). F, G- Showing decreased polysaccharides in kidney cortex of D+G groups after seven days (Fig. 3F) while, somewhat normal distribution of polysaccharides is observed after twenty-one-day (Fig. 3G). 


\subsection{2-Total protein}

Table 2 and figures 4, 5 illustrated the changes in total protein content in sections of the kidney cortex of the control and the different experimental groups. The diabetic groups exhibited a significant decrease in total protein content $(0.291 \& 0.198$ after seven and twenty-one days respectively) in the cuboidal cells of the convoluted tubules and the lobulated and atrophied glomeruli while degenerated glomerulus was negatively stained after seven (Fig. 5B) and twenty-one day (Fig. 5C). The kidney cortex of rats of Arabic gum groups showed a nonsignificant increase in total protein content which reached $0.828 \& 0.812$ after seven (Fig. 5D) and twenty-one days (Fig. 5E) respectively as compared to the control group (Fig. 5A). Kidney cortex of rats administrated Arabic gum post-alloxan injection (D+G) exhibited a significant decrease in total protein content which reached 0.713 after seven days (Fig. 5F) with a non-significant decrease after twenty-one days (Fig. 5G) which amounted to 0.784 as compared to the control value.

\begin{tabular}{|c|c|c|c|c|}
\hline Parameters & \multicolumn{4}{|c|}{ Total protein content } \\
\hline Time & \multicolumn{2}{|c|}{ Seven days } & \multicolumn{2}{|c|}{ Twenty-one days } \\
\hline Groups & Mean \pm S.D & $\begin{array}{l}\% \text { Change } \\
\text { vs control }\end{array}$ & Mean \pm S.D & $\begin{array}{l}\% \text { Change } \\
\text { vs control }\end{array}$ \\
\hline Control (C) & $0.808 \pm 0.087$ & $0.0 \%$ & $0.808 \pm 0.087$ & $0.0 \%$ \\
\hline Diabetic groups (D) & $0.291 * \pm 0.035$ & $-63.99 \%$ & $0.198 * \pm 0.023$ & $-75.49 \%$ \\
\hline $\operatorname{Arabic} \operatorname{gum}(\mathbf{G})$ & $0.828 \pm 0.137$ & $2.48 \%$ & $0.812 \pm 0.134$ & $0.50 \%$ \\
\hline $\mathbf{D + G}$ & $0.713^{*} \pm 0.185$ & $-11.76 \%$ & $0.784 \pm 0.189$ & $-2.97 \%$ \\
\hline
\end{tabular}

Table 2 - Showing total protein content in kidney cortex of the control and all the treated groups of adult male Albino rats - Each value represents the mean \pm standard deviation $(\mathrm{SD})$-* Significant difference from the control at $\mathrm{P} \leq 0.05$

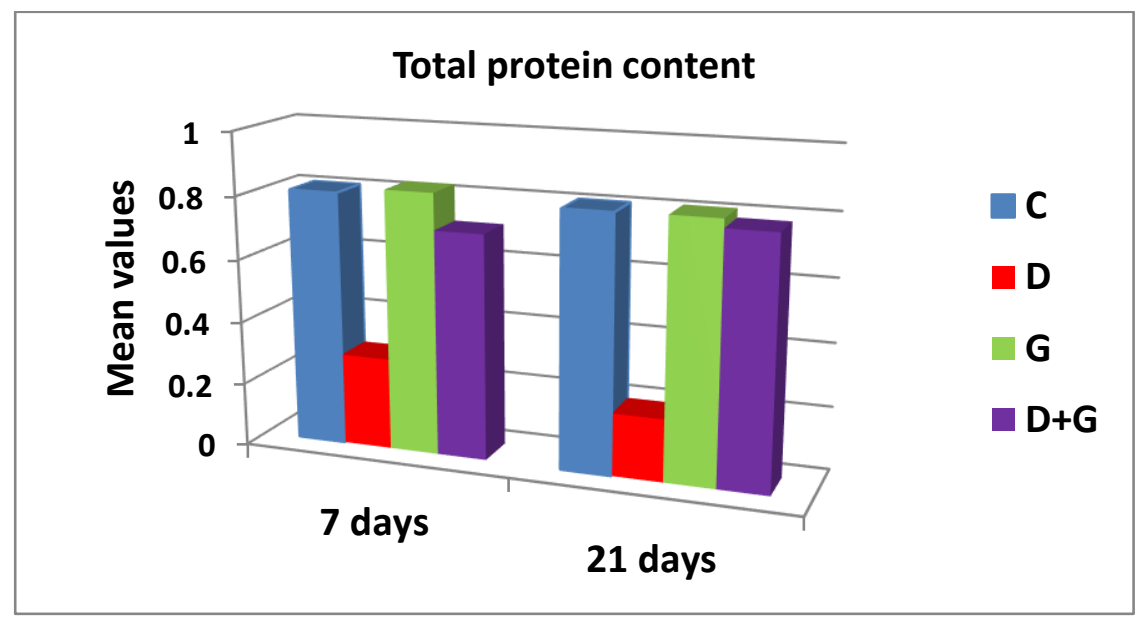

Fig. 4 - Showing mean values of total protein content relative to the control value 

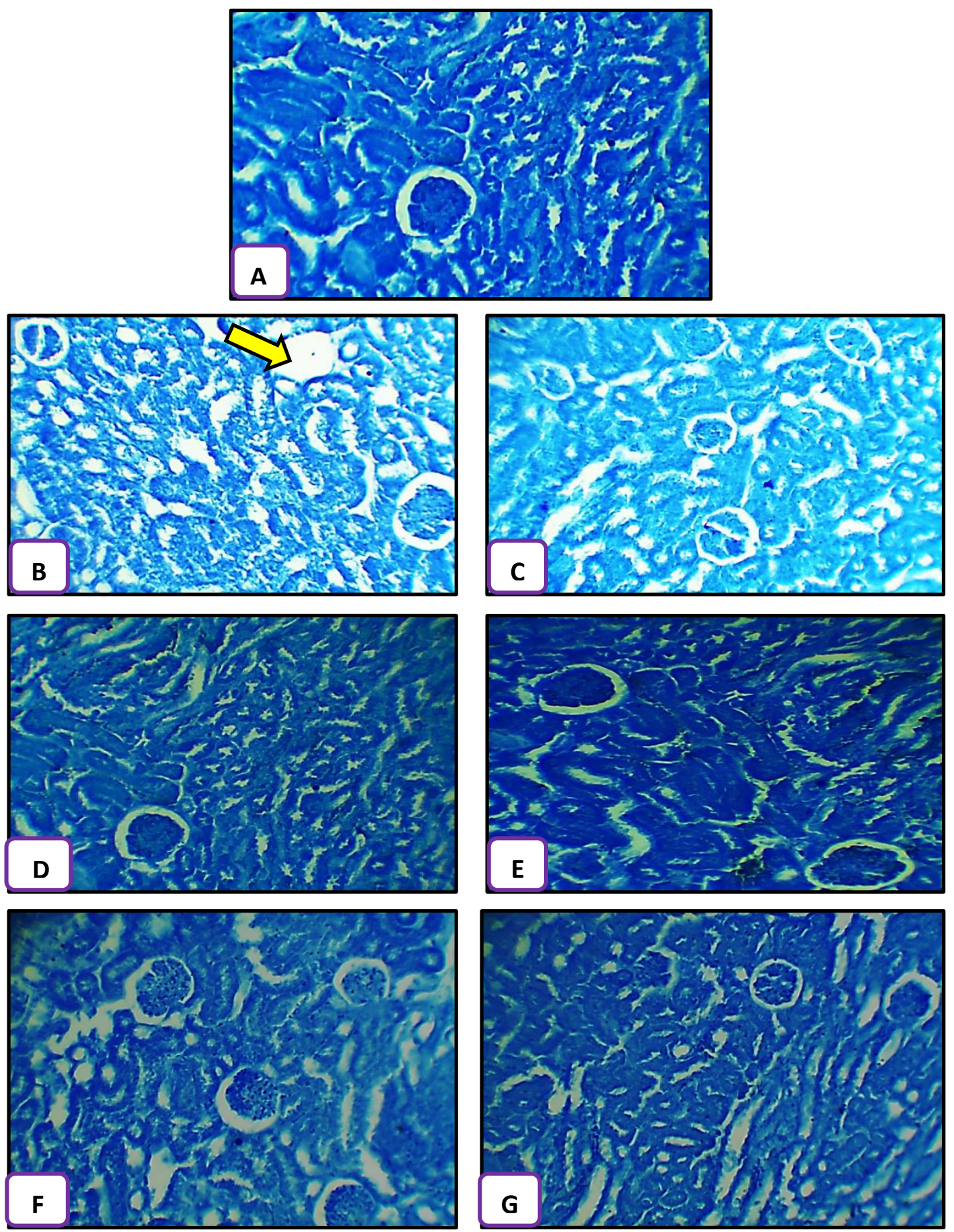

Figs. 5A-G- Photomicrographs showing the distribution of total protein in sections of the kidney cortex tissue of the control and all the treated groups (Mercuric bromophenol blue stain X 250)

A- Showing densely stained total protein all over the kidney cortex of the control group. B, C- Showing highly decreased total protein of the diabetic groups in the cuboidal cells of the convoluted tubules and the lobulated and atrophied glomeruli while degenerated glomerulus is negatively stained $(\rightarrow$ ) after seven (Fig. 5B) and twenty-one day (Fig. 5C). D, E - Showing normal content of total protein of Arabic gum groups all over the kidney cortex after seven (Fig. 6D) and twenty-one days (Fig. 5E). F- Showing decreased total protein in kidney cortex of $\mathbf{D + G}$ group after seven days as compared to the control group. $\mathbf{G}$-Showing somewhat normal distribution of total protein in kidney cortex of $\mathbf{D}+\mathbf{G}$ group all over the kidney cortex after twenty-one days. 


\section{$\underline{\text { 3.2.3-Total DNA content }}$}

Table 3 and figures 6, 7 illustrated the changes in total DNA content in sections of kidney cortex tissue of the control and the different experimental groups after seven and twenty-one days posttreatment. The kidney cortex of the diabetic groups exhibited a significant decrease in DNA content which reached 0.119 after seven days (Fig. 7B) and 0.108 after twenty-one days (Fig. 7C) as compared to the control group (Fig. 7A). Treatment with Arabic gum alone showed non-significant increases in the mean values of DNA content $(0.547 \& 0.571$ after seven (Fig. 7D) and twenty-one day (Fig. 7E) respectively) as compared to the control group. On the other hand, the kidney cortex of rats of $\mathbf{D + G}$ groups underwent a significant decrease in DNA content which amounted to 0.477 after seven days (Fig. 7F) with a non-significant decrease (0.513) after twenty-one days (Fig. 7G) as compared to the control group.

\begin{tabular}{|c|c|c|c|c|}
\hline Parameters & \multicolumn{4}{|c|}{ Total DNA content } \\
\hline Time & \multicolumn{2}{|c|}{ Seven days } & \multicolumn{2}{|c|}{ Twenty-one days } \\
\hline Groups & Mean \pm S.D & $\begin{array}{l}\% \text { Change } \\
\text { vs control }\end{array}$ & Mean \pm S.D & $\begin{array}{l}\text { \% Change } \\
\text { vs control }\end{array}$ \\
\hline Control (C) & $0.517 \pm 0.015$ & $0.0 \%$ & $0.517 \pm 0.015$ & $0.0 \%$ \\
\hline Diabetic group (D) & $0.119 * \pm 0.011$ & $-76.98 \%$ & $0.108 * \pm 0.010$ & $-79.11 \%$ \\
\hline $\operatorname{Arabic} \operatorname{gum}(\mathbf{G})$ & $0.547 \pm 0.039$ & $5.80 \%$ & $0.571 \pm 0.041$ & $10.44 \%$ \\
\hline $\mathbf{D}+\mathbf{G}$ & $0.477^{*} \pm 0.042$ & $-7.74 \%$ & $0.513 \pm 0.023$ & $-0.77 \%$ \\
\hline
\end{tabular}

Table 3 - Showing total DNA content in the kidney cortex of the control and all the treated groups of adult male Albino rats -Each value represents the mean \pm standard deviation $(\mathrm{SD})-*$ Significant difference from the control at $\mathrm{P} \leq 0.05$

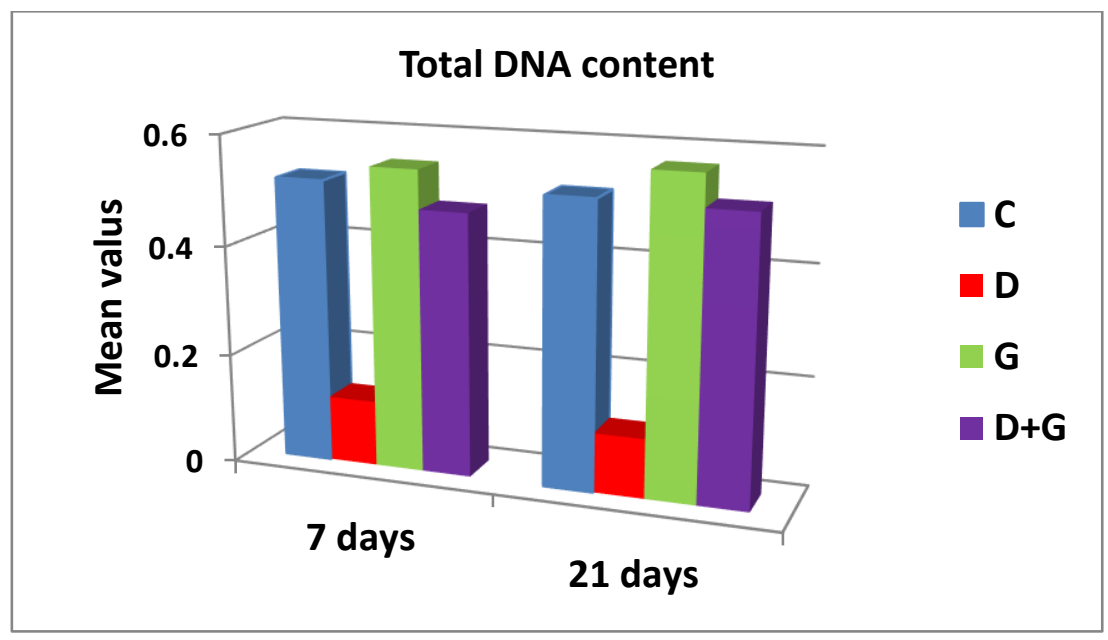

Fig. 6- Showing the mean values of total DNA content relative to the control value 

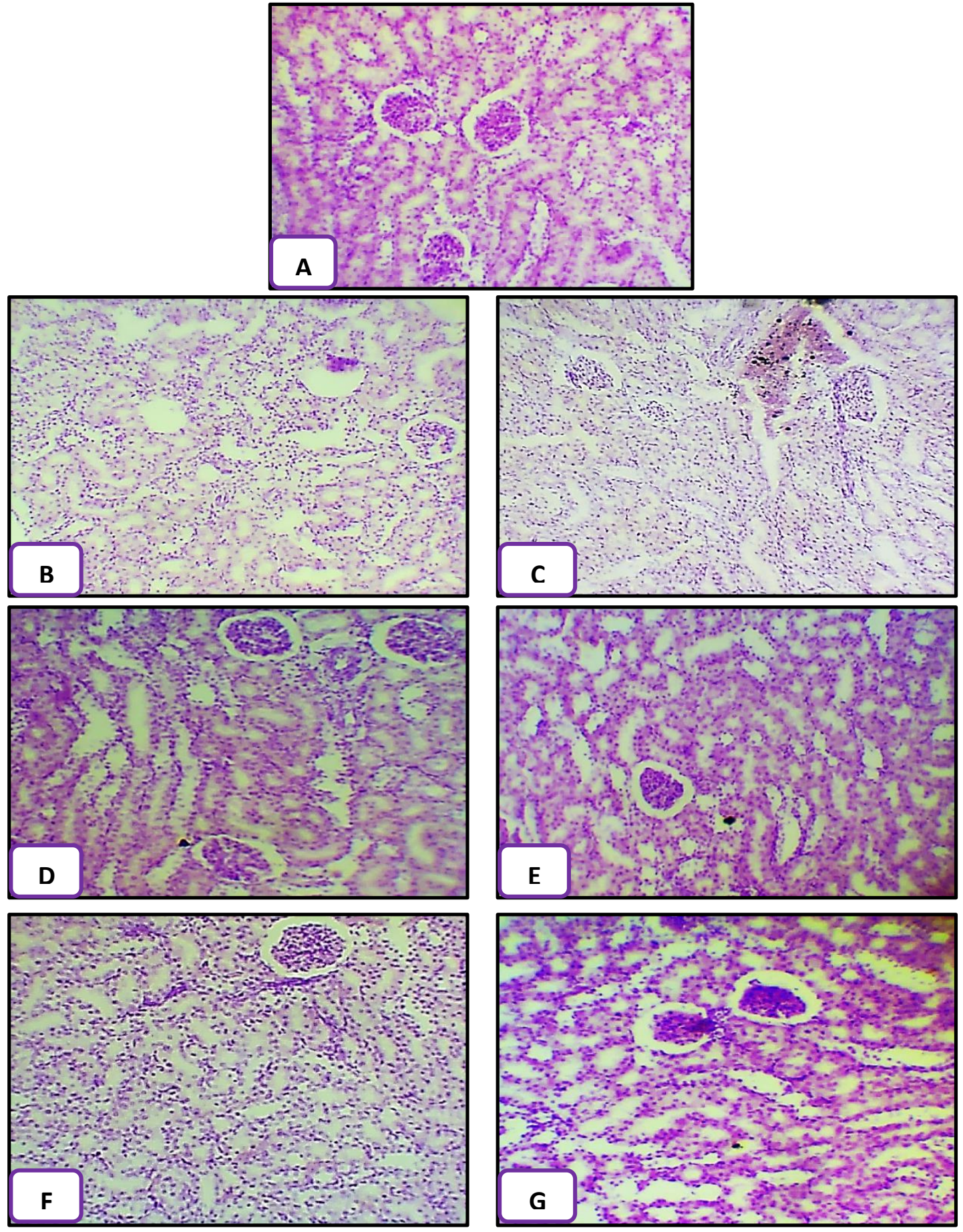

Figs. 7A-G- Photomicrographs showing the distribution of total DNA content in sections of the kidney cortex tissue of the control and all the treated groups (Feulgen reaction X250) A-Showing deeply stained DNA content in nuclei of the glomeruli and convoluted tubules of the control group. B, C- Showing faintly stained nuclei of the convoluted tubules of the diabetic groups, but few nuclei in the glomeruli are moderately stained others are negatively stained after seven (Fig. 7B) and twenty-one days (Fig. 7C). D, E- Showing normal DNA content in most nuclei of the glomeruli and convoluted tubules of Arabic gum groups after seven (Fig. 7D) and twenty-one days (Fig. 7E). F, G- Showing moderately stained DNA content in the convoluted tubules and the glomerulus of $\mathbf{D + G}$ group after seven days (Fig. 7F) and somewhat normal DNA content are observed after twenty-one days (Fig. 7G) as compared to the control group. 


\subsection{4-Amyloid- $\beta$ protein}

Table 4 and figures 8,9 showed the changes in amyloid- $\beta$ protein in sections of the kidney cortex of the control and all the treated groups after seven and twenty-one days post-treatment. The diabetic groups exhibited a significant increase in amyloid- $\beta$ protein content $(0.515 \& 0.524$ after seven (Fig. 9B) and twenty-one days (Fig. 9C) respectively) in the convoluted tubules and glomeruli of the kidney cortex all over the experimental periods relative to the control group (Fig. 9A). The kidney cortex of rats administrated Arabic gum alone exhibited nonsignificant increases in amyloid- $\beta$ protein content which reached 0.133 after seven days (Fig. 9D) and 0.133 after twenty-one days (Fig. 9E) post-treatment relative to the control group. While rats administrated Arabic gum post-alloxan injection exhibited a significant increase in amyloid- $\beta$ protein content which amounted to 0.145 after seven days (Fig.9F) and a non-significant decrease (0.127) after twentyone days (Fig. 9G).

\begin{tabular}{|c|c|c|c|c|}
\hline Parameters & \multicolumn{4}{|c|}{ Amyloid- $\beta$ protein } \\
\hline Time & \multicolumn{2}{|c|}{ Seven davs } & \multicolumn{2}{|c|}{ Twenty-one days } \\
\hline Groups & Mean \pm S.D & $\begin{array}{l}\% \text { Change } \\
\text { vs Control }\end{array}$ & Mean \pm S.D & $\begin{array}{l}\% \text { Change } \\
\text { vs Control }\end{array}$ \\
\hline Control (C) & $0.131 \pm 0.013$ & $0.0 \%$ & $0.131 \pm 0.013$ & $0.0 \%$ \\
\hline Diabetic group (D) & $0.515 * \pm 0.047$ & $293.13 \%$ & $0.524 * \pm 0.040$ & $300 \%$ \\
\hline Arabic gum(G) & $0.133 \pm 0.021$ & $1.53 \%$ & $0.133 \pm 0.011$ & $1.53 \%$ \\
\hline $\mathbf{D + G}$ & $0.145^{*} \pm 0.021$ & $10.69 \%$ & $0.127 \pm 0.029$ & $-3.05 \%$ \\
\hline
\end{tabular}

Table 4 - Showing amyloid- $\beta$ protein content in kidney cortex of the control and all the treated groups of adult male Albino rats -Each value represents the mean \pm standard deviation (SD) -* Significant difference from the control at $\mathrm{P} \leq$ 0.05

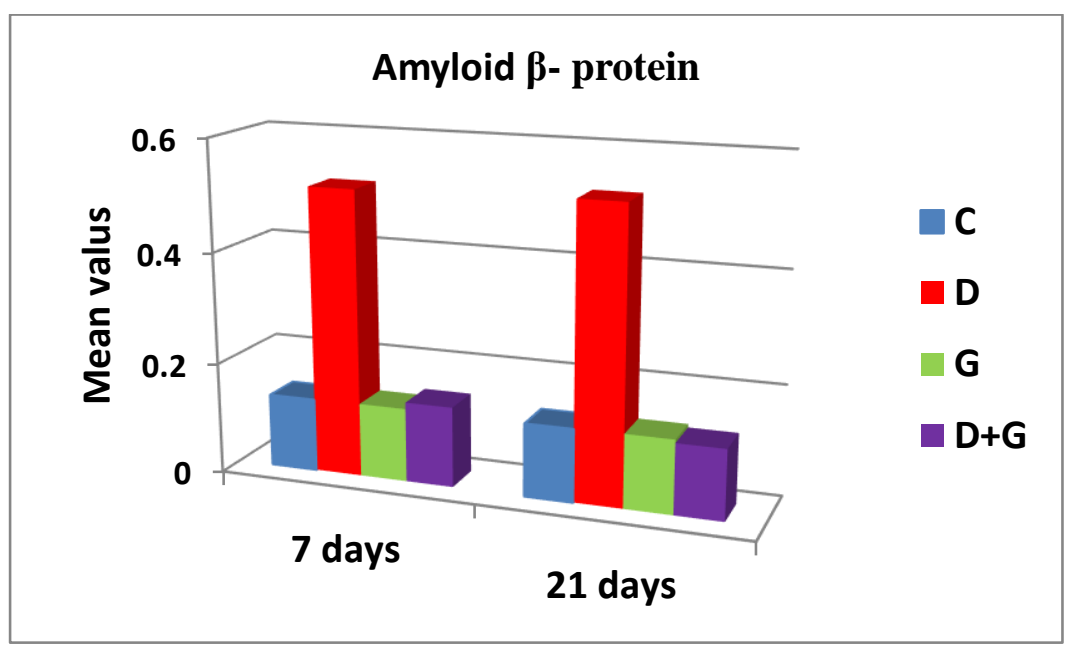

Fig. 8 - Showing the mean values of amyloid- $\beta$ protein relative to the control value 

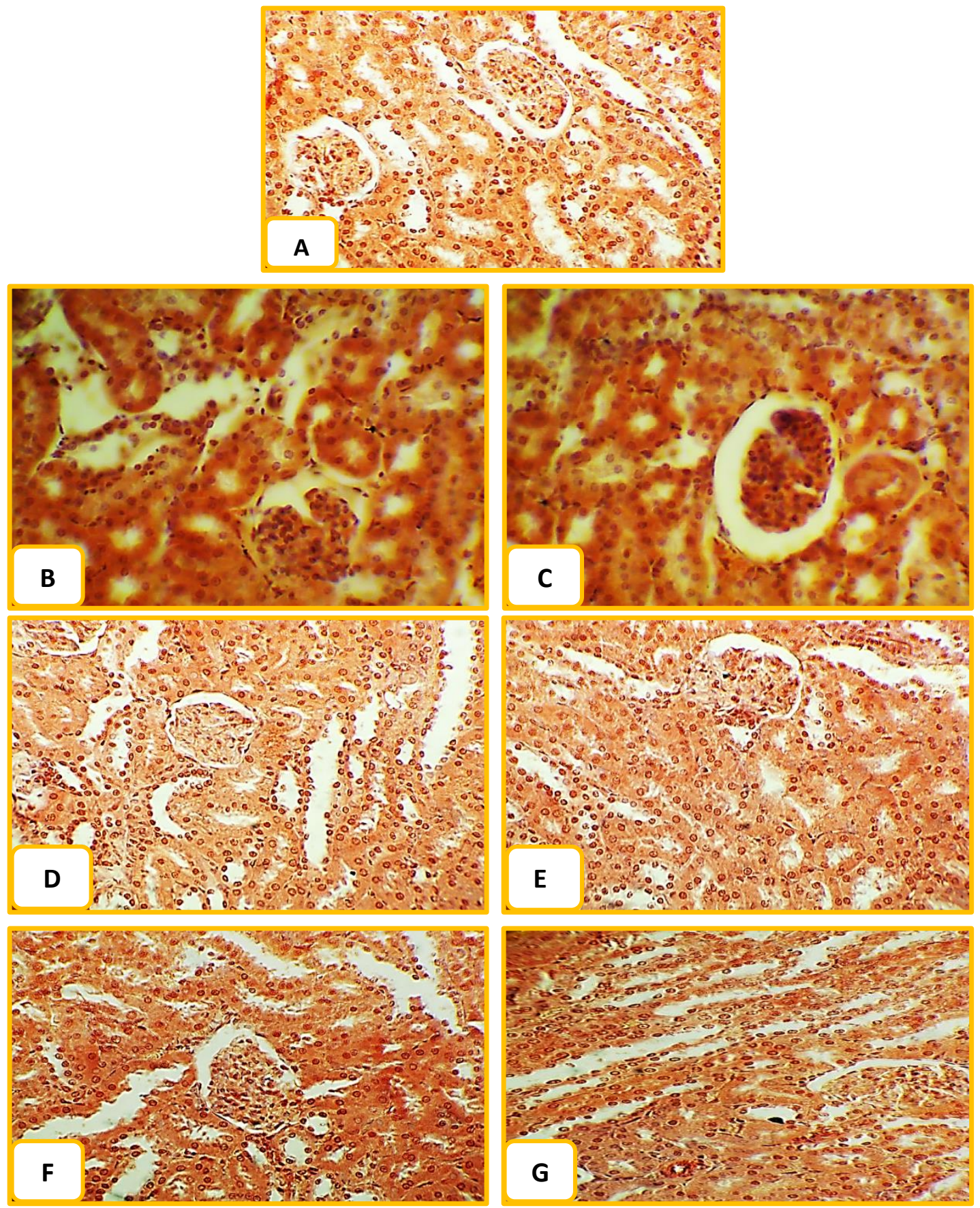

Figs. 9A-G- Photomicrographs showing the distribution of amyloid- $\beta$ protein in sections of the kidney cortex tissue of the control and all the treated groups (Congo red stain $X$ 250)

A- Showing faintly stained amyloid- $\beta$ protein all over the kidney tissue of the control group. B, C- Showing highly increased amyloid- $\beta$ protein in the glomeruli and convoluted tubules of the diabetic groups after seven (Fig. 9B) and twenty-one days (Fig. 9C). D, E- Showing normal distribution of amyloid- $\beta$ protein of Arabic gum groups all over the kidney cortex after seven (Fig. 9D) and twenty-one days (Fig. 9E). F, G- Showing increased amyloid- $\beta$ protein in some convoluted tubules of the kidney cortex of $\mathbf{D + G}$ group after seven days (Fig. $\mathbf{9 F}$ ) and somewhat normal distribution are observed after twenty-one days (Fig. 9G) as compared to the control group. 


\section{4-Discussion}

In the present study, highly increased collagen fibres were detected in and around the highly dilated and congested renal arteries, around the highly distorted glomeruli, around the hemorrhagic areas, in basement membranes of the convoluted tubules and the degenerated areas, and between the convoluted tubules after seven and twenty-one days post-alloxan injection. Phillips and Steadman (2002) reported that exposure of human renal proximal tubular cells to high glucose increased the amount of collagen IV and fibronectin in the culture supernatant and decreased the pathways which were responsible for their degradation. Moreover, the significant increase of collagen fiber deposition within the glomerulus indicated the occurrence of glomerulosclerosis due to chronic inflammation which was emphasized by the mesangial matrix hypercellularity with overproduction of extracellular matrix. Elenkov $\boldsymbol{e t}$ al. (2005) confirmed the inflammatory theory in chronic renal failure by the significant increase in lipid peroxidation end product MDA (Malondialdehyde) and C-reactive protein inflammatory marker. According to Meran and Steadman (2011) and Reich et al. (2013), the collagen-producing bone marrow-derived cells had been shown to contribute to tissue fibrosis in models of renal fibrosis. The same authors added that in response to kidney injury, fibrocytes mobilized and infiltrated into renal parenchyma and participate in fibrogenesis.

Also, the current results of the current study are in agreement with the results of Gerth et al. (2007) who showed that collagen type VIII (gene: COL8) increased expression in the glomerular as well as tubular compartments of renal biopsies in patients with the diabetic nephropathy. Furthermore, hyperglycemia facilitated reactive oxygen species (ROS) generation in various renal cells, including tubular cells and the high glucose-induced proliferation and activation of renal fibroblasts were mediated by ROS signaling (He et al., 2016). ElNabawia et al. (2017) realized that the presence of interstitial fibrosis is evidenced by the significant increase of collagen fiber deposition in the interstitium. Fibrosis might suggest the presence of chronic inflammation which was emphasized by the presence of peritubular inflammatory cells and fibroblasts. This is following the results of Helmy $\boldsymbol{e t}$ al. (2015) who found that fibroblasts secreted excess extracellular matrix and this, in turn, destroyed the normal interstitial architecture of the kidney.

In the present study normal distribution of collagen fibres that support the glomeruli, Bowman's capsules, basement membranes of the proximal and distal convoluted tubules were observed after seven and twenty-one days. According to Azzaoui $\boldsymbol{e t}$ al. (2015), the gums claimed therapeutic usefulness in hepatic and renal failure await further verification in animal models and humans. They added that no significant adverse or toxic actions have been associated with the use of Arabic gum. Fouda and Ismail (2018) reported that the histological examination of a kidney of rabbits treated with Arabic gum showed normal histological structure, in terms of intact Malpighian corpuscles and normal proximal renal tubules. Their obtained observation indicated normal kidney function, which may conclude the safe treatment of Arabic gum on the kidney function of rabbits.

In the current study, treatment with Arabic gum post-alloxan injection showed slightly increased collagen fibres deposition in between the convoluted tubules and in their basement membranes after seven days as compared to the control group while thin scattered collagen fibres which supported the glomeruli and convoluted tubules were observed after twenty-one days. Badreldin et al. (2014) showed marked expansion and hypercellularity of the interstitial area in adenine-treated rats $(0.75 \% \mathrm{w} / \mathrm{w}$ in the feed for 4 weeks), along with increased amounts of collagen-like material. These abnormalities were markedly attenuated in the adenine-treated rats that also received gum Acacia (GA 15\% w/v in drinking water). No changes were seen in either untreated or gum Acacia-treated controls. 
In the present study, results of the diabetic rats showed a marked diminution in PAS + ve materials in the cuboidal cells of the proximal and distal convoluted tubules, but lobulated and atrophied glomeruli were deeply stained all over the experimental periods. These results go in agreement with those of El-Missiry and El-Gindy (2000) who observed a decrease in glycogen content in sections of kidney tissue. Diminution of carbohydrates content that was observed in the present work was most probably consequent to signs of degeneration and inflammation manifested in this work or due to the damaging effect of alloxan on the cytoplasmic organelles especially Golgi apparatus and the associated enzymes. Increased PAS+ve materials in some glomeruli may be due to congestion observed in them since RBCs contain $10 \%$ of their weight carbohydrates (Abd Rabu, 2011). Decreased mucopolysaccharides content in the kidney of the diabetic rats had been explained by Tunez et al. (2003), they postulated that the decrease of glycogen content of rats treated with streptozotocin might be due to express of glycogenolysis.

In the present work, Arabic gum groups showed normal distribution of polysaccharides in the glomeruli and convoluted tubules of kidney cortex after seven and twenty-one days while, treatment of the diabetic rats with Arabic gum showed an improvement in polysaccharides content when compared to the diabetic group, but still less than the normal content after seven days. These effects may be due to the antioxidant nature of this plant. According to Poop and Cattley (1991), it seems clear that the increase of polysaccharides deposition in the basement membranes and brush borders of the renal tubules is a sign of glycogenesis. Also, Arabic gum contains high molecular polysaccharides and their calcium and magnesium salts, which on hydrolysis yield arabinose, galactose, rhamnose, and glucuronic acid (Eqbal and Aminah, 2014).

Histochemical results of this work showed highly decreased total protein in the cuboidal cells of the convoluted tubules and also in the lobulated and atrophied glomeruli while degenerated glomeruli were negatively stained after seven and twenty-one days and these results agree with those of Shaffie $\boldsymbol{e t} \boldsymbol{a l}$. (2010) who found marked diminution in protein content of the renal tubular cells in alloxan diabetic rats. They added that this decrease may be due to the ability of alloxan to generate free radicals in presence of suitable reducing agents, like reduced glutathione and oxygen. Alloxan exerts its DNA-damaging action, at least in part, by the production of free radicals and this may affect protein synthesis; this action can be modulated by common antioxidants, which can easily supplement the diet. This explanation is in agreement with those of Garber (1980) who reported that the decrease in serum albumin and total protein content of the diabetic rats may be due to decreased amino acids uptake and greatly decreased concentration of a variety of essential amino acids (Brosnan et al., 1984), reduction in protein synthesis which in turn may be due to the decrease in the amount and availability of mRNA (Wool $\boldsymbol{e}$ t al., 1986) and a reduction in ribosomal protein synthesis as a result of insulin deficiency (Jefferson et al., 1983).

Together with hyperglycemia, also increases the generation of intracellular ROS in the renal tubular epithelial cells, which mediate many negative biological effects, including oxidation of proteins and damage to DNA (Bonventre, 2012). The results of this study showed that rats treated with Arabic gum showed a non-significant increase in total protein content after seven and twenty-one days as compared to the control group while the diabetic rats treated with Arabic gum showed an increase in protein content in the renal tubules of kidney cortex as compared to the diabetic groups and this proved that Arabic gum is an effective antioxidant which can protect proteins against oxidation. Sierens $\boldsymbol{e t}$ al. (2001) stated that the antioxidant species may act in vivo to decrease the damage of protein content in tissues. Increased protein content in groups $\mathbf{D + G}$ indicated that Arabic gum is more effective in improving cells of kidney tissue dysfunction induced by alloxan. The improvement of protein profile in the treated group $\mathbf{D}+\mathbf{G}$ is in a 
harmony with increased serum insulin level where, insulin plays an important role in protein metabolism which stimulates amino acids uptake and protein synthesis and inhibits protein degradation in muscle and other tissues (Gilman, 2006). This caused an increase in the number of the experimental and clinical investigations directed toward the validation of the hypoglycemic (El-Ridi, 2001) and/or anti-diabetic properties of the different medicinal plants (Abdou $\boldsymbol{e t}$ al., 2011).

Amber et al. (2017) and Fouda and Ismail (2018) reported that blood biochemicals including total proteins, albumin, globulin, and high-density lipoprotein (HDL) concentrations significantly increased. They added that obtained results of blood biochemicals and enzyme activity may indicate that Arabic gum had a positive effect on protein metabolism, lipid profile, and liver function and consequently healthy status of rabbits treated with different doses of Arabic gum.

In the current study, the kidney cortex of the diabetic rats exhibited significant decreases in DNA materials all over the experimental periods as compared to the control group. The present study is supported by the work of Damasceno et al. (2011) who revealed that diabetes caused higher DNA damage confirming the interaction between hyperglycemia-induced genotoxicity and teratogenesis. These results declared the relationship between diabetes, oxidative stress, and oxidative DNA damage. According to Damasceno et al. (2014) oxygen and nitrogen species, the products of free radicals, which are dependent on fatty acid oxidation, can induce chromosomal damage in streptozotocininduced diabetes mellitus. They added that free radicals can also react with DNA bases, impairing their structure, and potentially leading to mutations. DNA oxidation is the most common type of damage. In the current study, the decrease of DNA content was associated with a decrease in protein content in kidney cells of diabetic rats. These results go in agreement with those of Blasiak et al. (2003) they reported that alloxan can damage DNA in normal cells, operating therefore as a genotoxic compound. They added that the observed DNA damage might be due to the induction of DNA strand breaks and/or the formation of alkali labile sites, which can be transformed into strand breaks in the alkaline comet assay. Also, El Nabarawy (2014) reported that diabetes can generate oxidative stress and DNA damage. The same author added that the ability of streptozotocin to generate free radicals in the presence of suitable reducing agents, like reduced glutathione and oxygen is well known. Streptozotocin exerts its DNA-damaging action, at least in part, by the production of free radicals and this action can be modulated by common antioxidants. DNA damage in chronic kidney disease patients was increased (Schupp et al., 2016). ROS further seemed to play a role in the induction of apoptosis (Brezniceanu et al., 2010; Daehn et al., 2014), cytokines, and uremic toxins being involved (Han et al., 2015). Accumulating evidence suggested that DNA damage as a result of oxidative stress can lead to genomic instability through multiple pathways (Noguti et al., 2011). Also, El-Nabawia et al. (2017) concluded that chronic renal failure resulted in two forms of cell death, necrosis, and apoptosis.

In the present study, Arabic gum treated groups showed deeply stained DNA materials in nuclei of the glomeruli and convoluted tubules while rats administrated Arabic gum post alloxan injection showed moderately stained DNA materials in the convoluted tubules and glomeruli after seven days; somewhat normal DNA content was observed after twenty-one days as compared to the control group. Ali et al. (2013) proved that DNA double-strand breaks were significantly increased in the kidney by adenine treatment. Gum Arabic reduced this effect significantly but was not able to restore the control levels. They added that induced apoptosis was almost totally suppressed by GA in rat kidney tissue. The present results are supported by the results of Ali $\boldsymbol{e t}$ al. (2015) who demonstrated that treatment with gum Arabic was able to abate genetic damage and oxidative stress following chronic renal failure in the kidney cells. The same authors added that treatment with gum 
Arabic mitigated (but not prevented completely) the levels of genetic damage in kidney cells by Comet assay. Moreover, Nasir et al. (2010 b) demonstrated a powerful anti-carcinogenic effect of gum Arabic as a result of the prophylactic activity of the xenobiotic against colon carcinoma in rodents.

In the current study, alloxan groups exhibited a significant increase in amyloid- $\beta$ protein content in the convoluted tubules and glomeruli of the kidney cortex all over the experimental periods relative to the control group. Amyloids are insoluble fibrous protein aggregates sharing specific structural traits. They are insoluble and arise from at least 18 inappropriately folded versions of proteins and polypeptides present naturally in the body (Alvarado et al., 2000). These misfolded structures alter their proper configuration such that they erroneously interact with one another or other cell components forming insoluble fibrils. They have been associated with the pathology of more than 20 serious human diseases in that abnormal accumulation of amyloid fibrils in organs may lead to amyloidosis and may play a role in various neurodegenerative disorders (Pulawski et al., 2012). Kadowaki et al. (2005) showed that amyloid deposition is associated with mitochondrial dysfunction and the resulting generation of reactive oxygen species (ROS), which can initiate a signaling pathway leading to apoptosis. Results of the present findings showed that administration of Arabic gum alone and Arabic gum post-alloxan injection showed somewhat normal deposition of amyloid protein content relative to the control group after seven and twenty-one days posttreatment. Singh et al. (2009 a \& b) declared that green pods and seeds of Acacia nilotica can provide the nutrients and therapeutic ingredients to prevent, mitigate and treat various diseases. Also, Sadeek (2018) showed that the high phenolic and flavonoids compounds of GA could protect the kidney.

\section{References}

Abdou, H. S.; Salah, S.H.; Abd El-Raouf, A. and

Abdel-Rahim, E. A. (2011):

Chromosomal aberrations and nucleic acids systems affected by some Egyptian medicinal plants used in treating female pregnant diabetic rats. American Journal of Molecular Biology, 1: 26-32.

Abd Rabu, M. (2011): Modulation of radiation injury in pregnant rats by bone marrow transplantation. M.Sc. Zoology Department, Faculty of Science, Al-Azhar University, Cairo.

Ali, B.H.; Al Balushi, K.; Al-Husseini, I.; Mandel, P.; Nemmar, A.; Schupp, N., and Ribeiro, D.A. (2015): Gum acacia mitigates genetic damage in adenine-induced chronic renal failure in rats. Eur. J. Clin. Invest., 45 (12): 1221-1227.

Ali, B.H.; Al-Salam, S.; Al Zaabi, M.; Waly, M.I.; Ramkumar, A.; Beegam, S.; AlLawati, I.; Adham, S.A. and Nemmar, A. (2013): New model for adenine-induced chronic renal failure in mice and the effect of gum acacia treatment thereon: comparison with rats. J. Pharmacol. Toxicol. Methods, 68: 384-393.

Alvarado, M.R.; Merkel, J.S. and Regan, L. (2000): A systematic exploration of the influence of the protein stability on amyloid fibril formation in vitro. P.N.A.S., 97 (16): 8979-8984.

Amber, K.H.; Abd El-Nabi, F.M.; Morsy, W.A. and Morsy, S.H.A. (2017): Gum Arabic as prebiotic in growing rabbit diet. Global Veterinaria, 19: 465-471.

Atar, D. and Hanssen, K. F. (2017): Type 2 diabetes and heart failure - more scrutiny wanted. Cardiology, 139:37-39.

Ayeleso, T.B.; Ramachela, K. and Mukwevh, E. (2018): Aqueous-methanol extracts 
of orange-fleshed sweet potato (Ipomoea batatas) ameliorate oxidative stress and modulate type 2 diabetes associated genes in insulin resistant $\mathrm{C} 2 \mathrm{C} 12$ cells. Molecules, 23(8):2058.

Azzaoui, K.; Hammouti, B.; Lamhamdi, A.; Mejdoubi, E. and Berrabah, M. (2015): The gum Arabic in the southern region of Morocco. J. Chem., 3(1): 99-107.

Badreldin, H.A.; Inuwab, I.; Al Zaabia, M.; Al Bahlanic, S.; Al Issaeic, H.; Ramkumara, A.; Madanagopala, T.; Nemmard, A. and Denise M. (2014): Renal and myocardial histopathology and morphometry in rats with adenine - induced chronic renal failure: influence of gum acacia. Cell Physiol. Biochem., 34:818-828.

Bastos, A.; Graves, D.; Loureiro, A.; RossaJunior, C.; Abdalla, D.; Faulin, T. et al. (2012): Lipid peroxidation is associated with the severity of periodontal disease and local inflammatory markers in patients with type 2 diabetes. J. Clin. Endocrinol. Metab., 97(8): 13531362 .

Blasiak, J.; Sikora, A.; Czechowska, A. and Drzewoski, J. (2003): Free radical scavengers can modulate the DNAdamaging action of alloxan. Acta Biochimica Polonica, 50 (1): 205210.

Bonventre, J.V. (2012): Can we target tubular damage to prevent renal function decline in diabetes? Semin. Nephrol., 32:452-462.

Brezniceanu, M.L.; Lau, C. J.; Godin, N. et al. (2010): Reactive oxygen species promote caspase-12 expression and tubular apoptosis in diabetic nephropathy. J. Am. Soc. Nephro., 21(6): 943-954.

Brosnan, J.T.; Man, K.C.; Hall, H.E.; Clobourne, S.A. and Brosnan, M.E. (1984): Interorgan metabolism of amino acids in streptozotocin-diabetic rat. Am. J. Physiol., 244: 151- 158.

Cheng, L.; Hu, Y.; Sun, J.; Zhou, M. and Jiang, Q. (2018a): DincRNA: a comprehensive web-based bioinformatics toolkit for exploring disease associations and ncRNA function. Bioinformatics, 34: 19531956.

Cheng, L.; Wang, P.; Tian, R.; Wang, S.; Guo, Q.; Luo, M. et al. (2018b). Lnc RNA2 target v2.0: a comprehensive database for target genes of lncRNAs in human and mouse. Nucleic Acids Res., 8(47):140-144.

Daehn, I.; Casalena, G.; Zhang, T. et al. (2014): Endothelial mitochondrial oxidative stress determines podocyte depletion in segmental glomerulosclerosis. Journal of Clinical Investigation, 124(4): 1608-1621.

Damasceno, D.C.; Netto, A.O.; Lessi, I.L.; Gallego, F.Q.; Corvino, S.B.; Dallaqua, B.; Sinzato, Y.K.; Bueno, A.; Calderon, I.M. and Rudge, M.V. (2014): Streptozotocin- induced diabetes models: pathophysiological mechanisms and fetal outcomes. Bio. Med. Res. Inter., 2014: 819065-819076.

Damasceno, D.C.; Volpato, G.T., and Sinzato, Y.K. (2011): Genotoxicity and fetal abnormality in streptozotocininduced diabetic rats exposed to 
cigarette smoke prior to and during pregnancy. Experimental and Clinical Endocrinology and Diabetes, 119: 549-553.

Drury, R., and Wallington, E. (1980): Carleton's Histological Technique. $4^{\text {th }}$ ed., Oxford. Univ. Press, New York.

Elenkov, I.J.; Iezzoni, D.G.; Daly, A.; Harris, A.G. and Chrousos, G.P. (2005): Cytokine dysregulation, inflammation and well-being. Neuro -immunomodulation, 12:255-269.

El-Missiry, M.A. and El Gindy, A.M. (2000): Amelioration of alloxan-induced diabetes mellitus and oxidative stress in rats by oil of Eruca sativa seeds. Annals of Nutrition and Metabolism, 44: 97- 100.

El- Nabarawy, S. K. (2014): Oxidative damage in embryo and placenta of streptozotocin-induced diabetic rats. The Egyptian Journal of Hospital Medicine, 55: 218-227.

El-Nabawia, F.; El-Safti, A.; Shireen A. and Mohammed, S.H. (2017): Light and electron microscopic studies of chronic renal failure using an adenine rat model. Menoufia Medical Journal, 30(1): 271-277.

El-Ridi, M.R. (2001): A possible hypoglycemic effect of some medicinal plants used in the United Arab Emirates. Bulletin of the Egyptian Society of Physiology and Science, 21: 9-16.

Eqbal, M.A. and Aminah, D.A. (2014): Blood lipid profile and liver lipid peroxidation in normal rat fed with different concentrations of Acacia senegal and Acacia seyal. International Journal of Nutrition and Food Engineering, 8:1292-1297.

Fouda, S.F. and Ismail, R.F. (2018): Is Arabic gum supplementation as a natural antioxidant useful in improving reproductive performance and antioxidant capacity of heat stressed rabbit does in Egypt? Egyptian J. Nutrition and Feeds, 21(3): 701716.

Gamal El-din, A. M.; Mostafa, A. M.; AlShabanah, O. A.; Al-Bekairi, A. M. and Nagi, M. N. (2003): Protective effect of Arabic gum against acetaminophen-induced hepatotoxicity in mice. Pharma. Res., 48:631-635.

Garber, A.J. (1980): The impact of streptozotocininduced diabetes mellitus on cyclic nucleotide regulation of skeletal muscle amino acid metabolism in the rat. J. Clin. Invest., 65: 478-487.

Gentile, S.; Piscitelli, P.; Viazzi, F.; Russo, G.; Ceriello, A.; Giorda, C. et al. (2017): Antihyperglycemic treatment in patients with type 2 diabetes in Italy: the impact of age and kidney function. Oncotarget, 8: 62039-62048.

Gerth, J.; Cohen, C.D.; Hopfer, U.; Lindenmeyer, M.T.; Sommer, M.; Grone, H.J. and Wolf, G. (2007): Collagen type viii expression in human diabetic nephropathy. Eur. J. Clin. Investig., 37:767-773.

Gilman, A.G. (2006): The Pharmacological Basis of Therapeutics. $11^{\text {th }}$ ed. Brunton, L.L.; Lazo, J.S. and Parker, K. L. editors. USA, pp: 1613-1644.

Han, H.; Zhu, J.; Zhu, Z. et al. (2015): P-cresyl sulfate aggravates cardiac dysfunction associated with chronic kidney disease by enhancing apoptosis of cardiomyocytes. Journal of the American Heart 
Association, 4 (6): 001852.

He, T.; Xiong, J.; Nie, L.; Yu, Y.; Guan, X.; Xu, X.; Xiao, T.; Yang, K.; Liu, L.; Zhang, D. et al. (2016): Resveratrol inhibits renal interstitial fibrosis in diabetic nephropathy by regulating ampk/nox4/ros pathway. J. Mol. Med., 94:1359-1371.

Helmy, A.M.; Sharaf El-Din, N.A.; Abd-El-Moneim, R.A. and Rostom, D.M. (2015): Histological study of the renal cortical proximal and distal tubules in adult male Albino rats following prolonged administration of titanium dioxide nanoparticles and the possible protective role of 1-carnosine. The Egyptian Journal of Histology, 38:126-142.

Jefferson, L.S.; Warren, S.L.; Peavy, D.E.; Miller, J.B.; Appel, M.C. and Taylor, T.M. (1983): Diabetes induced alterations in liver protein synthesis: changes in the relative abundance of mRNA for albumin and other plasma proteins. J. Biol. Chem., 258(2): 1369-1375.

Jiang, S; Xu, L.; Xu, Y.; Guo, Y.; Wei, L.; Li, $X$. and Song, W. (2020): Antidiabetic effect of Momordica charantia saponins in rats induced by high-fat diet combined with STZ. Electro. J. Biotechno., 43: 41-47.

Kadowaki, H.; Nishitoh, H.; Urano, F.; Sadamitsu, C. and Matsuzawa, A. (2005): Amyloid beta induces neuronal cell death through ROSmediated ASK1 activation. Cell Death Differ., 12 (1): 19-24.

Konstantinos, M.; Ioannidis, I.; Liatis, S.; Makrilakis, K.; Tentolouris, N. and Tsapogas, P. (2006): Pathophysiology of type 2 diabetes.
In: Diabetes in Clinical Practice. Wiley and Sons editions, London, pp: 43- 45.

Kumar, A.Y.; Nandakumar, K.; Handral, M. et al. (2011): Hypoglycaemic and antidiabetic activity of stem bark extracts Erythrina indica in normal and alloxan-induced diabetic rats. Saudi Pharm. J., 19:35-42.

Mazia, D.; Brewer, P.A. and Alfert, M. (1953): The cyto-chemical staining and measurement of protein with mercuric bromophenol blue. Biol. Bull., 104:57-67.

Meran, S. and Steadman, R. (2011): Fibroblasts and myofibroblasts in renal fibrosis. Int. J. Exp. Pathol., 92:158-167.

Misra, M. and Aiman, U. (2012): Alloxan: an unpredictable drug for diabetes induction? Indian J. Pharmacol., 44(4): 538-539.

Mohamed, M.M.A. (2010): Determination of trace elements in gum Arabic using X-ray fluorescence M.Sc. Thesis, Faculty of Science, University of Khartoum, Khartoum, Sudan.

Morad, H. and Mohamed, E. (2020): Antidiabetic effect of aqueous Corrigiola telephiifolia in streptozotocininduced diabetic rats. The Natural Products Journal, 10(1):61-68.

Nasir, O.; Wang, K.; Foller, M.; Bhandaru, M.; Sandulache, D.; Artunc, F.; Ackermann, T.F.; Ebrahim, A.; Palmada, M.; Klingel, K.; Saeed, A.M. and Lang, F. (2010b): Down regulation of angiogenin transcript levels and inhibition of colonic carcinoma by gum Arabic (Acacia senegal). Nutr. Cancer, 62:802-810.

Nishi, K. and Jayakrishnan, A. (2004): Preparation and in vitro evaluation of primaquine-conjugated gum 
Arabic microspheres. Biomacro

Molecules, 5:1489-1495.

Noguti, J.; Pereira, V.G.; Martins, A.M.; D'Almeida, V. and Ribeiro, D.A. (2011): Genomic instability in blood cells from murine model of mucopolysaccharidosis type I. J. Mol. Histol., 42:575-578.

Paget, E. and Barnes, M. (1964): Interspecies dosage conversion scheme in evaluation of results and quantitative application in different species. Evaluat.Drug Activities Pharmacometric, 1: 160-162.

Papadopoulou-Marketou, N.; Paschou, S.A.; Marketos, N.; Adamidi, S.; Adamidis, S. and KanakaGantenbein, C. (2018): Diabetic nephropathy in type 1 diabetes. Minerva Med., 109(3):218-228.

Pears, A. (1977): Histochemistry, Theoretical and Applied. $3^{\text {rd }}$ ed., Vol. 1. Churchill Livingstone, London.

Phillips, A.O. and Steadman, R. (2002): Diabetic nephropathy: the central role of renal proximal tubular cells in tubulointerstitial injury. Histol. Histopathol., 17:247-252.

Poop, J.A. and Cattley, R.C. (1991): Hepto-biliary system. In: Handbook of Toxicologic Pathology. Haschek, W.M. and Rousseaux, C.G. editions, Academic Press, San Diego, pp: 279 - 314.

Pulawski, W.; Ghoshdastider, U.; Andrisano, V. and Filipek, S. (2012): Ubiquitous amyloid. Applied Biochem. Biotechnol., 166 (7): 1626-1643.

Reich, B.; Schmidbauer, K.; Gomez, M.R.; Hermann, F.J.; Gobel, N.; Bruh, H.; Ketelsen, I.; Talke, Y. and Mack, M. (2013): Fibrocytes develop outside the kidney but contribute to renal fibrosis in a mouse model. Kidney Int., 84:7889.

Renard, D.; Lavenant-Gourgeon, L.; Ralet, M.C. and Sanchez, C. (2006): Acacia senegal gum: continuum of molecular species differing by their protein to sugar ratio, molecular weight and charges. Biomacromolecules, 11(7):26372649.

Sadeek, E.F.A. (2018): Effect of Arabic gum as prebiotics and Lactobacillus casei Shirota as probiotic on oxidative stress and renal function in adenineinduced chronic renal failure in rats. European Journal of Nutrition and Food Safety, 8: 29-46.

Salgueiro, A.C.F.; Folmer, V.; Bassante, F.E.M.; Cardoso, M.H.S.; Rosa, H.S. and Puntel, G.O. (2018): Predictive antidiabetic activities of plants used by persons with diabetes mellitus. Complement Ther. Med., 41:1-9.

Schupp, N.; Stopper, H. and Heidland, A. (2016): DNA damage in chronic kidney disease: evaluation of clinical biomarkers. 2016: 3592042 . Avialable on: https://www.hindawi.com/journals/ omcl/2016/3592042/

Shaffie, N.M.; Morsy, F.A.; Ali, A.G. and Sharaf, H.A. (2010): Effect of craway, coriander and fennal on the structure of kidney and islets of langerhan in alloxan-induced diabetic rats: histological and histochemical study. Researcher, 2(7): 27-40.

Sierens, J.; Hartley, J.A. and Campbell, M.J. (2001): Effect of phytoestrogen and antioxidant supplementation on oxidative DNA damage assed uses the comet assay. Mutat. Res., 7: 169 
$-176$.

Singh, B.N.; Singh, B. R.; Sharma, B.K. and Singh, H. B. (2009a): Potential chemoprevention of Nnitrosodiethylamine-induced hepatocarcinogenesis by polyphenolics from Acacia nilotica bark. Chemical- Biology Interactions, 181: $20-28$.

Singh, B.N.; Singh, B. R.; Singh, R.L.; Prakash, D.; Sarma, B.K. and Singh, H.B. (2009b): Antioxidant and antiquorum sensing activities of green pod of Acacia nilotica L. Food and Chemical Toxicology, 47: 778 786.

Skyler, J.S.; Bakris, G.L.; Bonifacio, E. et al. (2017): Differentiation of diabetes by pathophysiology, natural history and prognosis. Diabetes, 66:241255.

Svensson, M.K.; Afghahi, H.; Franzen, S.; Bjork, S.; Gudbjornsdottir, S.; Svensson, A. M. et al. (2017): Decreased systolic blood pressure is associated with increased risk of all-cause mortality in patients with type 2 diabetes and renal impairment: a nationwide longitudinal observational study of 27,732 patients based on the Swedish National Diabetes Register. Diab. Vasc. Dis. Res., 14: 226-235.

Tunez, L. ; Munoz, M.C. ; Ferjoo-Lopez, A.L. ; Valdvira, E. ; Bujalance-Arenas, L. and Montilla, P. (2003): Effect of melatonin on hyper lipidemic nephropathology under constant light exposure. J. Physiol. Biochem., 55(2): 104 -114.

Valle, S. (1986): Special stains in microwave oven. J. Histotechnol., 9:237-248.
Waer, H. F. and Helmy S. A. (2012): Cytological and histochemical studies on rat liver and pancreas during progression of streptozotocin induced diabetes and possible protection using certain natural antioxidants. The Egyptian Journal of Hospital Medicine, 48: 452- 471.

Wanner, C. (2017): Empa-regoutcome: the nephrologist's point of view. Am. J. Med., 130(6):63-72.

Wool, I.G.; Strire-Walt, W.S.; Karrhara, K.; Low, R.B.; Bailey, P. and Oyer, P. (1986): Mode of action of insulin in regulation of protein biosynthesis in muscle. Recent Progress in Hormone Research, 24:139-213.

Xu, Y. L.; Xu, K. F.; Bai, J. L.; Liu, Y.; Yu, R.B.; Liu, C.L. et al. (2016): Elevation of serum uric acid and incidence of type 2 diabetes: a systematic review and meta-analysis. Chronic Dis. Transl. Med., 2: 81-91.

Yokoyama, H.; Oishi, M.; Takamura, H. et al. (2016): Large-scale survey of rates of achieving targets for blood glucose, blood pressure and lipids and prevalence of complications in type 2 diabetes (JDDM 40). BMJ Op. Diab. Res. Car., 4 (1): 000294.

Zhang, X.; Zou, Q.; Rodruguez-Paton, A. and Zeng, X. (2017): Meta-path methods for prioritizing candidate disease miRNAs. IEEE/ACM Trans. Comput. Biol. Bioinform., 16(1):283-291.

Zou, Q.; Qu, K.; Luo, Y.; Yin, D.; Ju, Y. and Tang, H. (2018): Predicting diabetes mellitus with machine learning techniques. Front. Genet., 9:515. Available on: DOI: 10.3389/ fgene.2018.00515 